\title{
Experimental investigation of aerodynamic coefficients of the Holy Trinity Column in wind tunnel
}

\author{
Petr Michálek ${ }^{1, *}$ and Stanislav Hračov ${ }^{1}$ \\ ${ }^{1}$ Institute of Theoretical and Applied Mechanics of the Czech Academy of Sciences, Prosecká 76, 190 \\ 00 Prague 9, Czech Republic
}

\begin{abstract}
The analysis of the aerodynamic force coefficients of the Holy Trinity Column in Olomouc based on the experimental wind tunnel testing is presented. Two aerodynamic models corresponding to geometrical scales 1:75 and 1:150 were built using 3D-printer and tested in the smooth flow in order to define the global static wind effects. The larger model served as a reference case for the tests of the isolated column, while the model build with smaller scale enabled also the experimental examination of the influence of the closest surroundings. The comparison of the aerodynamic coefficients obtained from the testing of both models for various wind speeds confirms their similarity and interchangeability. The independence of the coefficients on Reynolds number, Re, were successfully verified and the presented coefficients were determined for $\mathrm{Re}=2.7 \cdot 10^{5}$ for a large number of angles of wind attack. The significant decrease in the static wind load due to the surrounding buildings were observed. The obtained results can broaden the knowledge of wind load related to this type historical monuments and can be useful when deciding about their global maintenance, a type of remedial work or their conservation.
\end{abstract}

\section{Introduction}

The historic buildings, bridges and monuments are subjected to weather load for centuries. They are important part of the Czech national heritage and present a development of architecture, town planning art and cultivation of the landscape. The most valuable ones are inscribed on the UNESCO World Heritage List, which underlines the need for preserving them for future generations.

The Holy Trinity Column in Olomouc in the Czech Republic was completed in 1754 and its main purpose was to celebrate the Catholic Church and faith for ending a plague epidemic in Moravia. It is located at the Upper Square in the historical centre of Olomouc. Among the other Marian (plague) columns in the Czech Republic, the Holy Trinity Column is the biggest baroque sculptural group in the Czech Republic with its height of $35 \mathrm{~m}$. It consists of three levels with 18 statues of saints and a central column with gilded coppers sculptures of the Holy Trinity accompanied by the Archangel Gabriel on the top.

\footnotetext{
*Corresponding author: michalek@itam.cas.cz
} 
The column was inscribed on the UNESCO World Heritage List in the year 2000. The photo of the column in the full scale, the scale model and its reference area is presented in Fig. 1. The motivation to this study was to investigate wind loads on the historic structures, particularly Marian (plague) columns, which are present in many Czech and Moravian cities and towns, besides Olomouc in Kutná Hora, Brno, Prague, etc. The choice of the Holy Trinity Column in Olomouc for the wind tunnel testing follows from its geometrical dimensions, especially the height, and importance in terms of the Czech Republic.
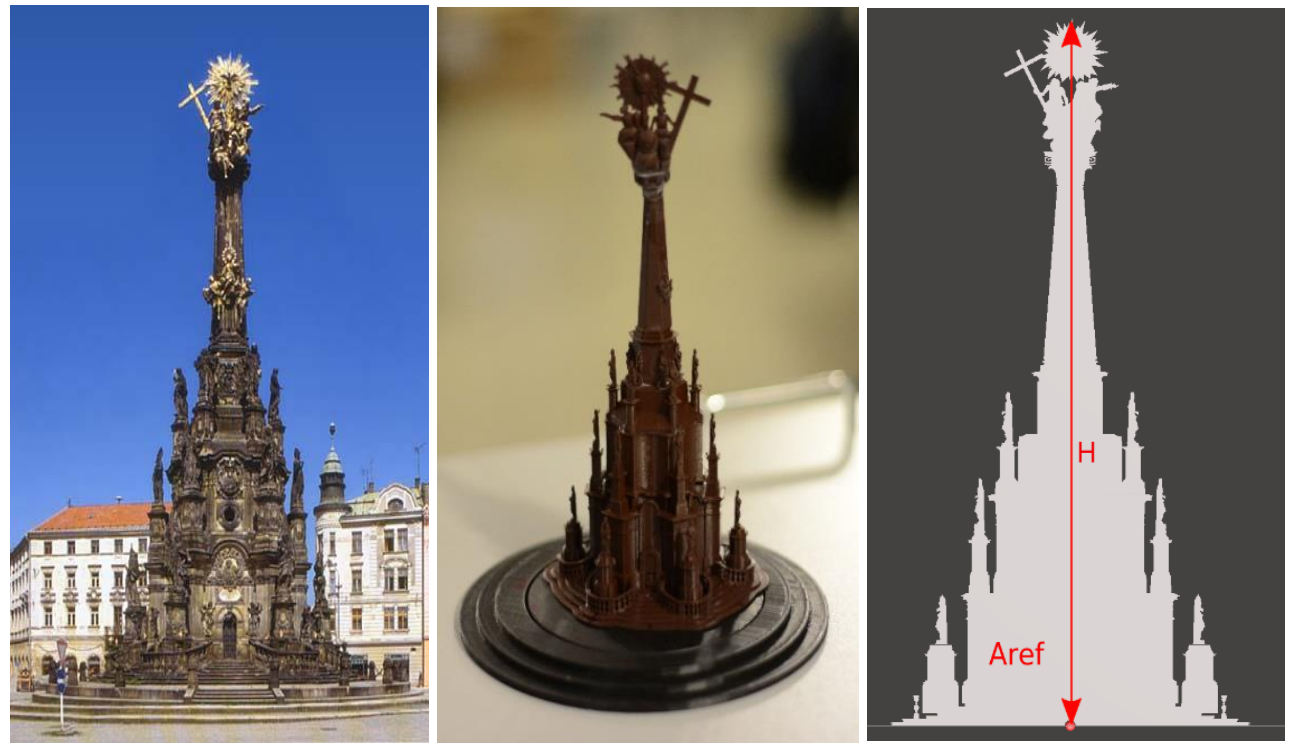

Fig. 1. The Holy Trinity Column in Olomouc [1] (left), its scale model (center) and reference area (right).

The care of historic buildings, bridges and other objects, their conservation and management progressively developed in the 20th century. The methods of the care deal principally with the historic object itself at its location. The diagnosis and monitoring of static and dynamic wind loads and other loads, e.g. façade pollution on the historic objects are performed mostly using non-destructive methods and sensors. Gentile and Saisi [2] have conducted experimental modal analysis of the Paderno iron arch bridge from 1889. Sýkorová et al. [3] have analysed carbon air pollution in deposits on chosen building materials of Prague Castle. Perez-Monserrat et al. [4] monitored façade soiling as a maintenance strategy for the sensitive built heritage at former Maudes Workers Hospital in Madrid. Carter [5] analysed two transporter bridges from the years 1900 and 1907 located in the United Kingdom using modern finite element analysis.

Wind tunnels can be used in testing parts of historic buildings and structures. Bláha et. al [6] identified failures of architectural heritage due to wind effects. Pospíšil et al. [7] studied surface degradation of a complex architectural form due to atmospheric pollution in a climatic wind tunnel. Wind tunnel modelling in conservation of historical structures was presented also by Pospíšil et al. [8]. A comprehensive summary of methods used in building conservation can be found in Drdácký et al. [9]. Petráňová et al. [10] modelled environmental load on the medieval mosaic at St. Vitus cathedral in Prague using climatic wind tunnel and other methods.

The European Union issued a report in 2018 [11] stating, “... research results are inadequately transferred into risk management practices and guidelines, and the transfer of knowledge to improve public awareness in cultural heritage protection is still insufficient." 
Present work is adding more research results to improve the knowledge base in wind loads on historic structures, which is unfortunately not as high as it should be, especially in the case of the World Heritage List objects.

\section{Experimental setup}

The static measurements were carried out in the Climatic Wind Tunnel of the Institute of Theoretical and Applied Mechanics of the Czech Academy of Sciences. This wind tunnel is located at Centre of Excellence Telč, it is a closed-circuit type, and it is equipped with a heating/cooling exchanger to control the air temperature between $-10{ }^{\circ} \mathrm{C}$ and $+40{ }^{\circ} \mathrm{C}$.

Two scale plastic models of the Holy Trinity Column were 3D-printed from the 3D digital model obtained from the City of Olomouc. The models were designed and build in two scales 1:75 (large model) and 1:150 (small model) in order to verify the independence of the results on the Reynolds number. Moreover, the small model was also utilized for study of the influence of surroundings. The blocks of neighbouring buildings forming the Upper Square in Olomouc, where the column is located, were carved from polystyrene in similar scale 1:150. The small column model with blocks of neighbouring buildings installed in the aerodynamic section of the wind tunnel is presented in Fig. 2.

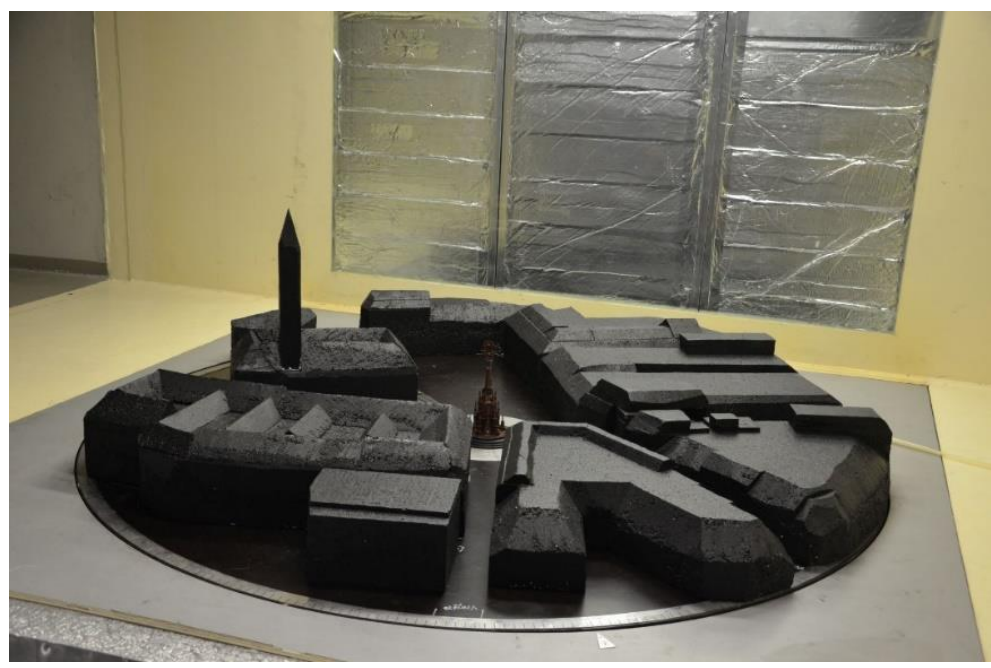

Fig. 2. The small scale model (1:150) of the column with surrounding buildings.

The static wind forces, i.e. three forces and three moments acting on the model were measured using the ATI Mini40 force and torque transducer. The sensor was mounted inside the centre of the turning table in the aerodynamic section and the base of the scale models were fixed to it via $3 \mathrm{~mm}$ thin spacer plate using screws. The plate created a sufficient distance between the model base and the wind tunnel floor so all forces and moments from the model were transferred into the transducer only.

At first, for selected incoming wind flow directions, the multiple measurements of both models were carried out for mean wind speed ranging from $5 \mathrm{~m} / \mathrm{s}$ to $20 \mathrm{~m} / \mathrm{s}$ in order to check the independence of the mean values of aerodynamic coefficients on Re. The testing was performed in almost smooth air flow with low turbulence intensity $I=1.6 \%$. Based on the test results the mean flow velocity was chosen equal to $20 \mathrm{~m} / \mathrm{s}$, which corresponds in the case of the small model $\mathrm{Re}=2.7 \cdot 10^{5}$ based on the model height $H(0.22 \mathrm{~m})$. The wind speed was measured with Pitot-static tube in front of the models at $44 \mathrm{~cm}$ height above wind tunnel 
floor. The models were subjected to wind load from several directions corresponding to angles of attack, $\alpha$, ranging from $0^{\circ}$ to $360^{\circ}$ with a step of $5^{\circ}$. The wind directions and their orientation to cardinal points are defined in the Fig. 3 together with basic dimensions of the column in metres, i. e. the total column width, central column width and side statue distance. The studied area with the Holy Trinity Column is marked with red circle and corresponds with wind tunnel turntable in the scale 1:150.

The top statues are oriented so that the cross is on the left when viewing the column from the south as in Fig. 1. In addition, the vertical plane of the top statue is oriented ca. 30 degrees from the west-east plane, i.e. ca. 120 degrees in the resulting wind direction. The large model (1:75) was measured only as an isolated structure, while the smaller one $(1: 150)$ also with surrounding buildings. All measurements were conducted with sampling frequency of $1000 \mathrm{~Hz}$ and length of recorded signal was $30 \mathrm{~s}$.

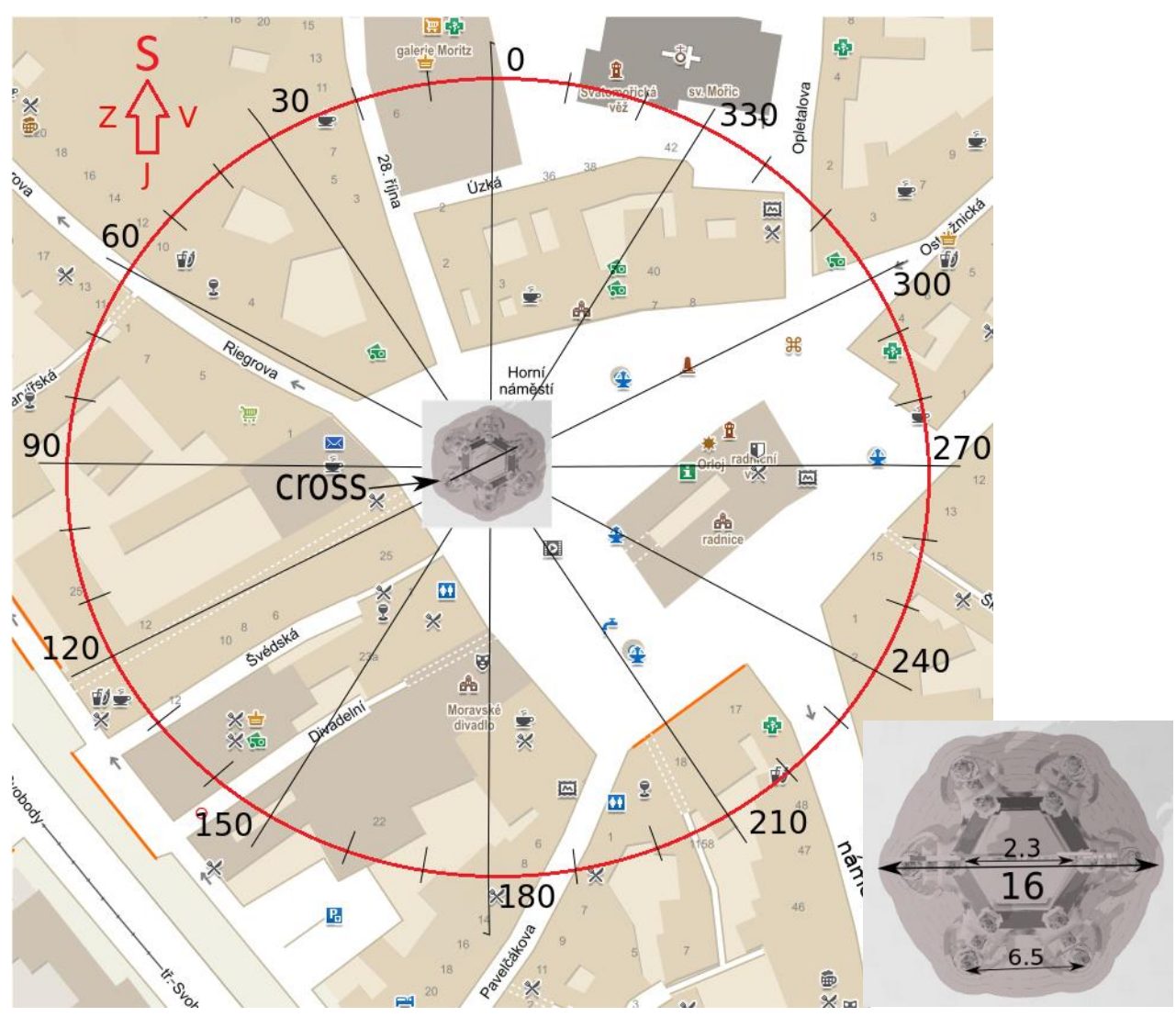

Fig. 3. Map of the Upper Square in Olomouc and column dimensions (inset).

\section{Results}

The effect of the static wind load can be defined by means of non-dimensional aerodynamic coefficients that can be afterwards applied to assessment of a real structure. The global drag coefficient for individual wind angle $\alpha$ was determined as

$$
C d(\alpha)=2 F_{\text {tot }}(\alpha) /\left(\rho V_{\text {ref }}^{2} A_{\text {ref }}\right)
$$


where $F_{\text {tot }}$ is the global measured force calculated from the mean values of force components in along-wind and across-wind directions $F u$ and $F w$

$$
F_{\text {tot }}(\alpha)=\left(F_{W}(\alpha)^{2}+F_{U}(\alpha)^{2}\right)^{1 / 2}
$$

In $\mathrm{Eq}(1), \rho$ is air density $\left[\mathrm{kg} / \mathrm{m}^{3}\right], V_{\text {ref }}[\mathrm{m} / \mathrm{s}]$ is the reference velocity at the top of the column and $A_{\text {ref }}\left[\mathrm{m}^{2}\right]$ is reference area of the column $\left(6.855 \cdot 10^{-3} \mathrm{~m}^{2}\right.$ for small model and $2.742 \cdot 10^{-2}$ $\mathrm{m}^{2}$ for large model). In our case, the reference area was chosen as cross-section corresponding to direction $\alpha=120^{\circ}$ (see Fig. 1), for which the area is maximal, and includes also the respective areas of the side statues. The standard drag coefficient in the wind direction, $\alpha$, was evaluated as

$$
C d_{F U}(\alpha)=2 F_{U}(\alpha) /\left(\rho V_{r e f}^{2} A_{r e f}\right)
$$

and similarly the across-wind component of global drag coefficient was calculated as

$$
C d_{F W}(\alpha)=2 F_{W}(\alpha) /\left(\rho V_{r e f}^{2} A_{r e f}\right)
$$

The global moment coefficients were defined likewise in the form

$$
C_{M t}(\alpha)=2 M_{t o t}(\alpha) /\left(\rho V_{r e f}^{2} A_{r e f} H\right)
$$

The global and directional drag coefficients $C d, C d_{F u}$ and $C d_{F w}$, respectively, calculated from the recorded data for large and small models without surrounding buildings as functions of the angle of attack, $\alpha$ is presented in Fig. 4. The similarity and interchangeability of both models is evident. The shape of all curves confirms a certain geometrical symmetry of the structure. The coefficients and their course are affected by two main structural factors. The first represents the hexagonal shape of the column cross section with the statues at its corners corresponding to angles $\alpha$ from $0^{\circ}$ to $360^{\circ}$ with the angular step $60^{\circ}$. The second factor is the orientation of the gilded statue of the Holy Trinity. In general, the global coefficient, $C d$, varies for both models in the range of $0.83-1.11$. The highest peaks of $C d$ correspond to the wind blowing directly onto the corner rows of statues at angles $\alpha=0^{\circ}, 60^{\circ}, 180^{\circ}$ and $240^{\circ}$, for which the gilded statue is oriented almost perpendicular to. On the contrary, the minima are related to the gilded statue parallel with the wind, which is blowing at right angle to side of the hexagonal cross section, i.e., between the corner rows of statues. As expected, the major part of $C d$ represents the along-wind coefficient, $C d_{F u}$. The across-wind coefficient, $C d_{F w}$ oscillates in the range of ca. 0 to 0.3 nearly periodically with the period equal to $30^{\circ}$. The moment coefficient, $C M t$, has a similar character to the $C d$ having the highest values in the interval from $0^{\circ}$ to $60^{\circ}$ and from $180^{\circ}$ to $240^{\circ}$, while the minimum can be found at $\alpha=$ $140^{\circ}$ see Figure 6.

The influence of the surrounding buildings onto the drag coefficients is shown in Fig. 5, where all drag coefficients for small model with (w. build.) and without buildings (no build.) are depicted. The comparison of both cases clearly shows that the buildings greatly reduce the wind load on the column, but certain peaks can still be found. In particular, the peaks of $C d$ and $C d_{F u}$ at ca. $60^{\circ}$ and $310^{\circ}$ correspond with directions where the wind flow comes through streets (street names in the figure) straight onto the column and is not blocked with buildings of the Upper Square. The values of perpendicular component $C d_{F w}$ with and without buildings is in general comparable, only for the angles from $0^{\circ}$ to ca. $40^{\circ}$ and from $315^{\circ}$ to $360^{\circ}$ a certain increase occurs. The $C d$-no build. curve was not added, because it would coincide with the $C d F u$-no build. curve. The differences between the curves $C d F w$ no build. and $C d F w$-w. build. in the interval $320^{\circ}$ to $330^{\circ}$ can be caused by the influence of the street Riegrova, which is almost perpendicular to this interval of wind direction and can create a channel for the wind flow. 


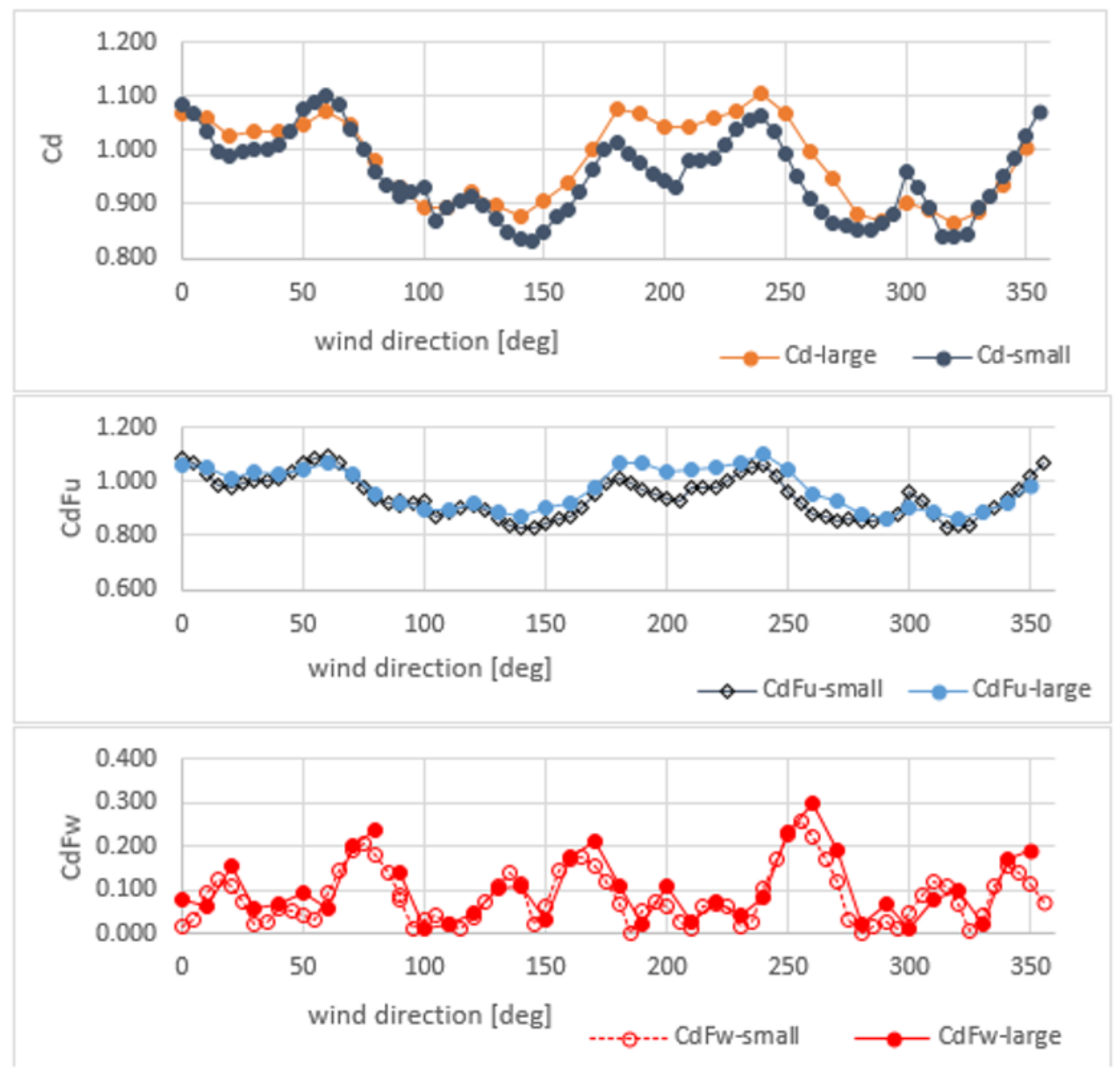

Fig. 4. Coefficients of drag for small and large models alone.

A significant reduction of momentums in the case with buildings was observed similarly to forces. Fig. 6 presents momentum coefficients for small model with (w. build.) and without (no build.) buildings. The maximal and minimal values of $C M t$ correspond with the orientation of top gilded statue, i. e. minimal value of $C M t$ was detected when the top statue was parallel or near to parallel to the main wind direction at $120^{\circ}$ and $315^{\circ}$. Maximal $C M t$ value corresponds with the orientation of top statue perpendicular to the main flow and in the range of angles around it about $30^{\circ}$ and $210^{\circ}$. 


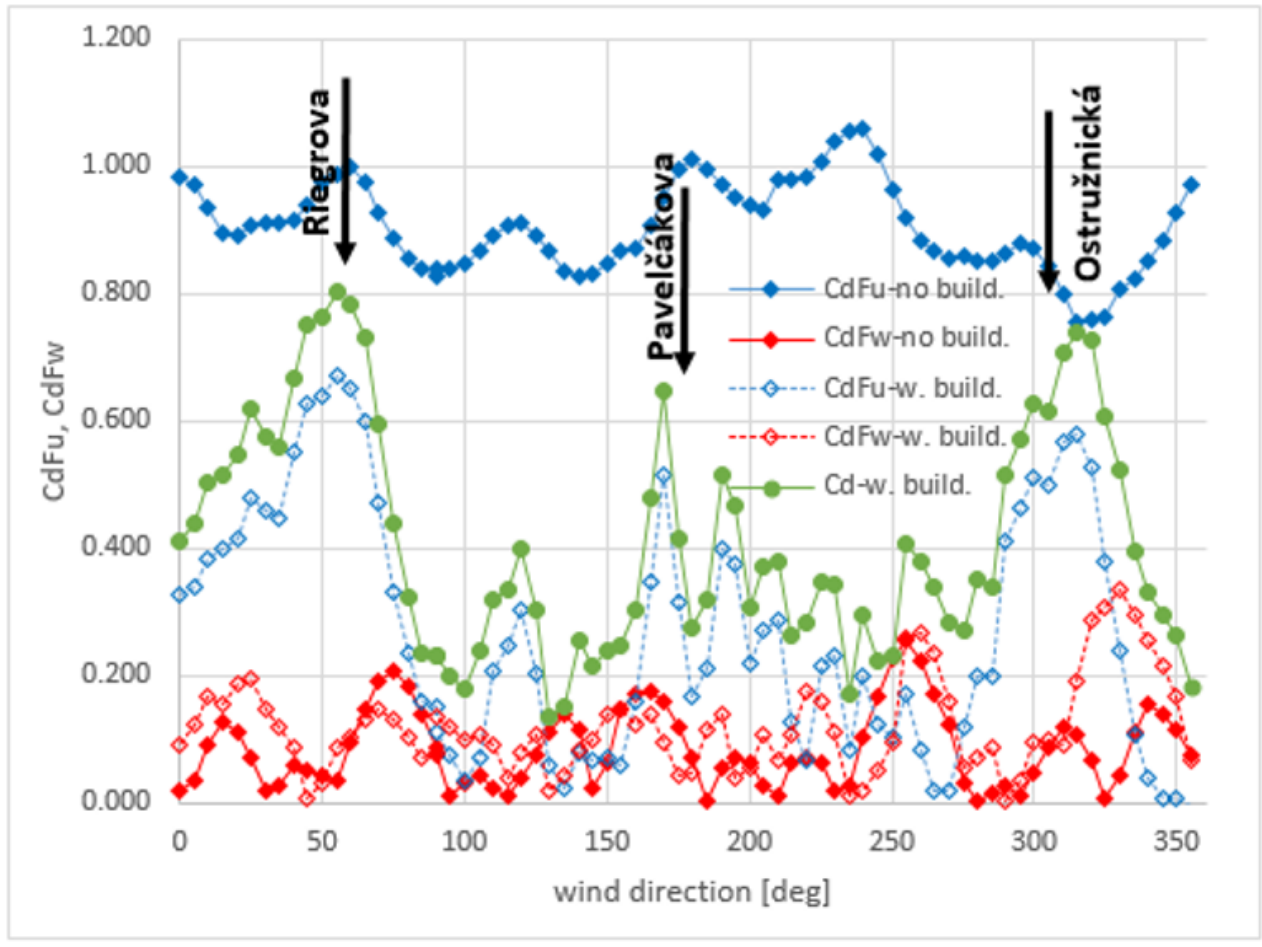

Fig. 5. Coefficients of drag for small model with and without buildings.

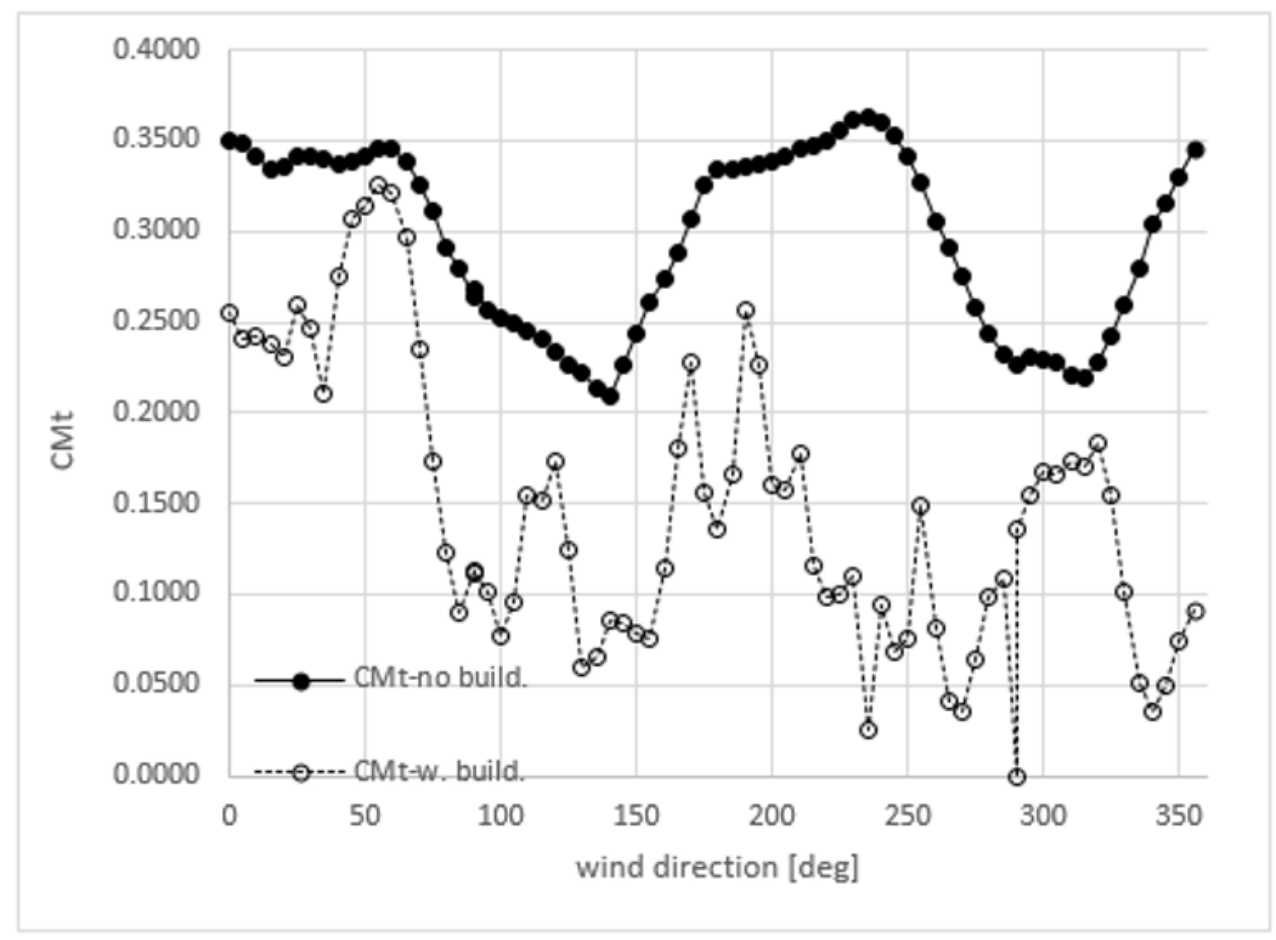

Fig. 6. Momentum coefficients for small model with and without buildings. 


\section{Conclusions}

Static force and torque measurements of two scale models of the Holy Trinity Column in Olomouc were performed in the wind tunnel at Centre of Excellence Telč. The effects of model scale, Reynolds number, orientation with respect to wind direction and buildings around the column were investigated in detail. The static wind load acting on the base of the column was expressed by means of mean values of non-dimensional aerodynamic coefficients that can be useful for a future analysis of similar historical monuments. The test revealed, that the value and the trend of the coefficients with changing wind direction is strongly affected by the orientation of the sculptures of the Holy Trinity and geometrical symmetry of the structure. The typical cross section of the lower part of the column can be idealized by a hexagon and thus two significant groups of the wind directions can be distinguished. The first represents the cases, when the wind is blowing directly onto the corner, while in the second case the wind is blowing perpendicularly to the side of the idealized hexagon. The measured total drag coefficient of the isolated column was ranging from 0.83 to 1.11 and the moment coefficient varied from 0.21 to 0.36 . As expected, the presence of buildings reduces the wind load on the column even in the cases when wind direction was aligned with the streets leading to the Upper Square. The decrease in the maximum of drag coefficient to $C d=0.8$ was determined. Also the moment coefficient was reduced significantly. The obtained results can extend the knowledge about the characteristic wind load at such unique structures and can be helpful for the engineers and preservationists dealing with a design of maintenance works.

This study was supported by the grant project DG18P02OVV040 "Monuments in motion", NAKI program II, provided by the Ministry of Culture of the Czech Republic. Authors would also like to thank The Olomouc City Hall for providing the digital 3D model of the Holy Trinity Column.

\section{References}

1. https://cs.wikipedia.org/wiki/Sloup_Nejsv\%C4\%9Bt\%C4\%9Bj\%C5\%A1\%C3\%AD_T rojice_(Olomouc)

2. C. Gentile, A. Saisi, Constr. Build. Mat. 25, 3709-3720 (2011)

3. I. Sýkorová, M. Havelcová, A. Zeman, H. Trejtnarová, Sci. Total Envir. 409, 4606-4611 (2011)

4. E.M. Perez-Monserrat, R. Fort, M.J. Varas-Muriel, Int. J. Arch. Herit. 12, 5, 816-827 (2017)

5. A.J. Carter, Project Report, (St. Hugh's College, Oxford 2007)

6. J. Bláha, M. Drdácký, S. Pospíšil, Proceedings of the International Conference on Heritage, Weathering and Conservation, HWC 2006, 409-415 (2006)

7. S. Pospíšil, M. Drdácký, Z. Slížková, D. Knotková, Ph. Delpech, Proceedings Heritage, Weathering and Conservation, London, 447-452 (2006)

8. S. Pospíšil, M. Drdácký, Z. Slížková, J. Lesák, D. Knotková, Proceedings Safeguarded Cultural Heritage (SAUVEUR Project), 1, 397-408 (2006)

9. M. Drdácký, Z. Slížková, J. Valach (eds), ITAM AS CR (2015) (in Czech)

10. V. Petráňová, J. Valach, S. Kuznetsov, S. Pospíšil, Proc. of the Third Intl. Conf. on Advances in Civil, Structural and Construction Engineering (2015)

11. Safeguarding Cultural Heritage from Natural and Man-Made Disasters, A comparative analysis of risk management in the EU, European Comission Report (2018) 